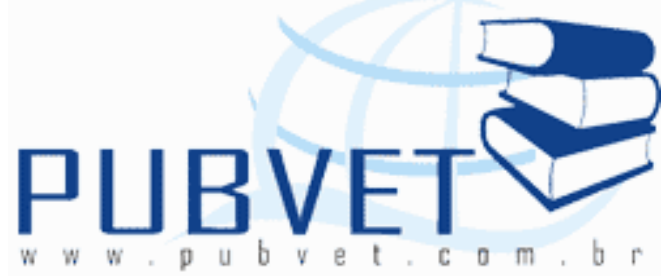

PUBVET, Publicações em Medicina Veterinária e Zootecnia.

\title{
Avaliação hematológica em cães errantes da região urbana de Maringá-PR
}

Rejane Machado Cardozo ${ }^{1}$, Raquel Reis ${ }^{1}$, Maria José Baptista Barbosa ${ }^{1}$, Camila Oliveira Rosa Alcalá2 ${ }^{2}$ Michele Ferreira de Assis ${ }^{2}$

${ }^{1}$ Docentes do curso de Medicina Veterinária da Universidade Estadual de Maringá.

${ }^{2}$ Acadêmicas do $5^{\circ}$ ano do curso de Medicina Veterinária da Universidade Estadual de Maringá.

\section{Resumo}

Uma ferramenta de grande importância para a clínica de cães e gatos é o hemograma completo. Este pode ser utilizado na busca pelo diagnóstico, indicando o prognóstico e o monitoramento da resposta à terapia. Já o hemograma simples, na maioria dos casos, se faz um recurso de diagnóstico limitado, entretanto, estabelece um ponto de partida para o diagnóstico rápido e preciso. Este trabalho tem por objetivo avaliar o perfil hematológico de cães recolhidos aleatoriamente na região urbana de Maringá-PR, discutindo, então, algumas das mais prováveis causas dessas alterações, considerando o fato destes cães serem animais errantes.

\section{Introdução}

A convivência dos animais de estimação como cães e gatos junto aos seres humanos é evidenciada ao longo da história. Tais animais, 
quando não recebem uma higiene adequada, vacinação e controle de endoparasitas e ectoparasitas, podem transmitir várias zoonoses tais como leishmaniose, babesiose, erliquiose, leptospirose, entre outras (NOGUEIRA, et. al. 2002).

A hematologia é o estudo associado dos elementos celulares do sangue e dos fatores de coagulação e pode ser estendida para incluir a citologia de líquidos não sanguíneos (KERR, 2003).

O hemograma completo é uma ferramenta importante na clínica de cães e gatos, podendo ser utilizado em casos clínicos, na busca diagnóstica, prognóstica e monitoramento da resposta a terapia. Embora, na maioria dos casos, isoladamente, o hemograma apresenta-se como recurso limitado na busca pelo diagnóstico. Com raras exceções, Cinomose, Babesia, Erlichia sp. Hemogramas típicos de piometra ou leptospirose, por exemplo, ele estabelece um ponto de partida para o diagnóstico rápido e preciso (GONZÁLEZ, 2005).

Uma contagem de leucócitos fora da faixa de normalidade deve-se a uma alteração no número de neutrófilos e/ou linfócitos. Sendo esses os tipos de leucócitos que mais contribuem para a contagem total. Já um número anormal de outros leucócitos (eosinófilos, basófilos ou monócitos) é insuficiente, em quase todos os casos, para alterar os valores totais de leucócitos além da faixa de normalidade. De modo geral, leucocitose deve-se ao número aumentado de neutrófilos e/ou linfócitos, e leucopenia deve-se a um número diminuído de neutrófilos (BUSH, 2004).

As zoonoses estão intimamente relacionadas às condições sanitárias, principalmente a uma boa higiene dos animais. Estas representam um importante problema de saúde publica com ênfase nos países subdesenvolvidos. Os animais domésticos são, na maioria das vezes, os mais acometidos e, posteriormente, o homem. A avaliação dos hemogramas dos cães permite informar às pessoas que convivem próximas a estes animais os reais perigos de se contaminarem, visando deixar a população consciente de que uma boa educação sanitária aliada a 
bons cuidados com os animais pode reduzir a incidência destas zoonoses ao mínimo.

Este trabalho tem por objetivo avaliar o perfil hematológico de cães recolhidos aleatoriamente na região urbana de Maringá-PR, apresentar as principais alterações quantitativas leucocitárias, eritrocitárias e plaquetárias no hemograma completo de cães, relacionando-as com as principais enfermidades encontradas na clínica médica.

\section{Material e Métodos}

Foram avaliados 32 cães a partir de três meses de idade, de ambos os sexos, que foram recolhidos da região urbana de Maringá-PR, sendo encaminhados para o Hospital Veterinário (HV) do Departamento de Medicina Veterinária/UEM, Campus Regional de Umuarama-PR. Esses animais foram alojados em gaiolas individuais e, após o período de três dias, foram realizadas as coletas sanguíneas pela punção na veia jugular, utilizando-se seringas e agulhas estéreis, sendo o material armazenado em recipientes com anticoagulante (EDTA - ácido etilenodiaminotetracético) e imediatamente homogeneizado. As amostras foram encaminhadas para o Laboratório de Análises Clínicas do HV para as análises das séries branca e vermelha do sangue e plaquetas. Os dados foram catalogados, analisados e classificados de acordo com a compatibilidade ou não com os valores de referência para a espécie.

\section{Resultados e Discussão}

Após análise laboratorial das 32 amostras de sangue, os resultados foram: na série vermelha (Figura 1), as hemácias encontravam-se em 8 amostras (25\%) dentro e em 24 (75\%) abaixo dos padrões da fisiologia [5,5 - 8,5 x $10^{6}$ u/L]. Na avaliação do hematócrito, 17 amostras (53\%) apresentavam-se dentro e 15 (46\%) abaixo dos níveis fisiológicos [37 $55 \%$ ]. Na hemoglobina, foram $13(40 \%)$ dentro e 19 (60\%) abaixo dos valores de referência [12 - $18 \mathrm{~g} / \mathrm{dL}]$. As alterações da série vermelha podem ocorrer nas anemias hemolíticas, decorrentes de hemoparasitas e, 
também, em casos de anemia hipoplásica, por deficiências nutricionais protéicas, minerais e/ou vitamínicas (KERR, 2003). De acordo com LOPES et. al. (2007), as anemias raramente são resultado de uma doença primária, mas, sim, de um processo patológico generalizado. Consequentemente, para um tratamento mais direcionado, é necessário o conhecimento da causa da mesma.

$\mathrm{Na}$ análise das proteínas totais, foram 24 amostras (75\%) dentro, 7 (22\%) acima e $1(3 \%)$ abaixo dos níveis fisiológicos $[6,0-8,0 \mathrm{~g} / \mathrm{dL}]$. Segundo BUSH (2004), as dietas com proteínas muito baixas fornecidas por períodos muito longos ou até mesmo a inanição total resultam em concentrações de proteínas totais e albumina baixa, justificando as amostras que apresentaram níveis abaixo dos padrões fisiológicos, decorrentes da má alimentação a que esses animais estão submetidos, logo, uma ingestão protéica deficiente. Outra possível causa de hipoproteinemia é uma má absorção.

Segundo Kaneco et al (1997), essa má absorção e perdas protéicas por diarreias, são um quadro característico da infecção viral, na cinomose e/ou parvovirose e nos casos de verminoses intensas, que causam dano epitelial. Como as amostras coletadas são de animais errantes e visto que estes não receberam uma vacinação e/ou vermifugação adequada, estando expostos a estes vírus, pode-se então justificar o quadro de hipoproteinemia da amostra coletada.
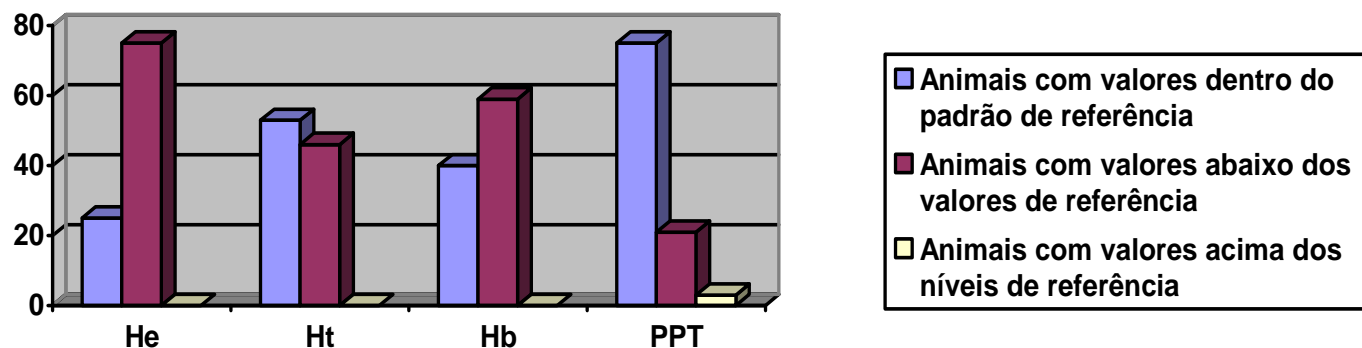

Figura 1- Análise hematológica das séries vermelhas e proteína plasmática total. 
Nos resultados da série branca (Figura 2), os leucócitos totais estavam em 5 amostras (15\%) acima dos valores de referência e em 27 amostras $(85 \%)$ nos padrões de referência $\left[6,0-17,0 \times 10^{3} \mathrm{uL}\right]$. Os neutrófilos estavam em 7 amostras (26\%) com valores acima dos níveis fisiológicos, em 12 (37\%) abaixo do padrão fisiológico e em 12 (37\%) dentro dos valores de referência [60-77\%]. A neutropenia é a diminuição do número absoluto de neutrófilos circulantes, seja pela diminuição ou alteração na produção de células na medula óssea, pelo aumento da marginalização ou mesmo pela destruição dos neutrófilos circulantes (NELSON; COUTO, 2010). Além disso, as causas de neutropenia podem ser decorrentes de infecções bacterianas, viroses, infecções por rickettisias, protozoários, estados debilitantes e caquéticos (GARCIANAVARRO, 2005).

$\mathrm{Na}$ contagem dos eosinófilos, 13 amostras (40\%) foram superiores aos valores de referência, 2 (6\%) ficaram abaixo destes valores e 17 (54\%) estavam nos padrões fisiológicos [2-40\%]. Eosinofilia é definida como o aumento no número absoluto de eosinófilos circulantes. Em cães, a eosinofilia é frequentemente vista naqueles com infecções por nematódeos e ancilóstomos (NELSON; COUTO, 2006). O fato dos cães avaliados nesse trabalho serem cães errantes, e provavelmente não receberem nenhum tipo de vermífugo, justifica a eosinofilia encontrada, em concordância com os dados levantados pelo estudo parasitológico. A eosinopenia é comumente observada como parte de um leucograma de stresse e geralmente é de pequena relevância clínica (NELSON; COUTO, 2006).

Em relação aos linfócitos 18 amostras (56\%) estavam dentro do valor de referência, 7 amostras (22\%) estavam abaixo e 7 amostras (22\%) estavam acima do valor de referência [12-30\%]. A linfocitose é o aumento do número de linfócitos circulantes acima do máximo normal da espécie. Ocorrendo nas ocasiões tais como doenças infecciosas de natureza crônica, doenças virais, protozoonoses e subdesnutrição, a 
linfopenia é a diminuição do número de linfócitos circulantes abaixo do mínimo normal da espécie. A linfopenia ocorre geralmente quando há uma queda na capacidade e resposta imunológica. As principais linfopenias são na fase aguda da inflamação, linfopenia das doenças prolongadas e linfopenia iatrogênica. (GARCIA-NAVARRO, 2005).
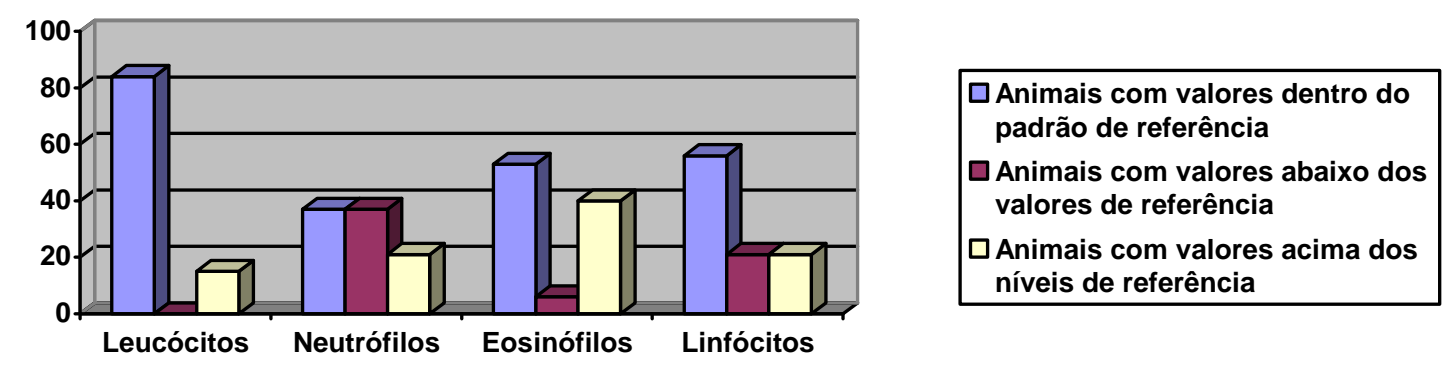

Figura 2 - Análise hematológica das séries brancas

A contagem de plaquetas (Figura 3 ) demonstrou que 5 amostras (15\%) estão dentro dos níveis fisiológicos e que 27 (85\%) estão abaixo dos valores de referência [200.000 - $500.000 \mathrm{uL}$, caracterizando um quadro de trombocitopenia. A trombocitopenia pode ser causada pelos seguintes mecanismos: produção diminuída de plaquetas, destruição, consumo, sequestro e/ou distribuição anormal e perdas (LOPES et al., 2007). A causa mais comum é a trombocitopenia por destruição, justamente por serem animais de regiões endêmicas de ehrlichiose (BREITSCHWERDT, 1997).

Segundo Manuel (2010), a ehrlichiose monocítica canina é uma doença infecciosa e que pode ser encontrada em todo o mundo, sendo transmitida pelo carrapato Rhipicephalus sanguineus, provocando alterações inespecíficas e multissistêmicas.

A ehrlichia platys é responsável pela enfermidade denominada Trombocitopenia Infecciosa Cíclica dos cães, acometendo as plaquetas (BREITSCHWERDT, 1997). 


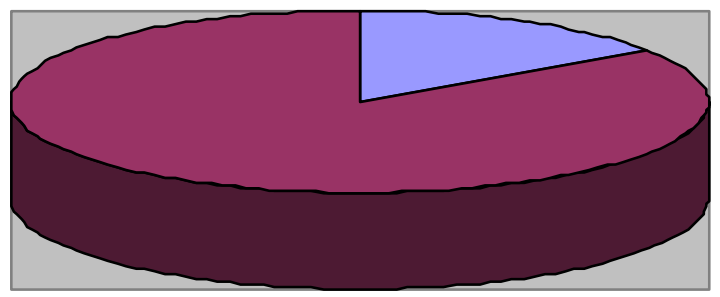

\begin{tabular}{|l|}
\hline Animais com plaquetas \\
dentro do padrão de \\
referência (15\%) \\
Animais com plaquetas \\
abaixo do padrão de \\
referência (84\%)
\end{tabular}

Figura 3 - Análise hematológica das plaquetas

\section{Conclusão}

Após a análise dos resultados totais, observa-se uma variação hematológica dos animais errantes, devido à exposição a um grande número de enfermidades e pelo potencial de transmissão delas, ficando mais evidente os dados obtidos em relação a plaquetas. Isto sugere que grande parte dos animais errantes estão infectados por rickettsias, sendo interessante o estudo epidemiológico dessas enfermidades.

\section{Referências}

BREITSCHWERDT, E. B. As Riquetisioses. In: ETTINGER, S. J.; FELDMAN, E. C. Tratado de medicina interna veterinária. V.1, 4 ed. São Paulo: Manole, 1997. Cap. 67, p. 54349.

BUSH, B. M. Interpretação de resultados laboratoriais para clínicos de pequenos animais. 1. ed. São Paulo: ROCA, 2004, p. 28-148.

GARCIA-NAVARRO, C. E. K. Manual de Hematologia Veterinária. 2 a Ed. São Paulo, 2005. p. 62-70.

GONZÁleZ, F.H.D.; SANTOS, A. P. Anais do 2 Simpósio de Patologia Clínica Veterinária da Região sul do Brasil, Realizado em Porto Alegre, no ano de 2005. Porto Alegre: UFRGS, 2005.

KANECO, J.J.; HARVEY, J.W.; BRUSS, M.L. Clinical biochemistry of domestic animals. 5.ed. California: Academic, 1997.

KERR, M.G. Exames Laboratoriais em Medicina Veterinária. 2. ed. São Paulo: Roca, 2003. p. $61-80 .$.

LOPES, S.T.A.; BIONDO A. W.; SANTOS. A. P. Manual de Patologia Clínica Veterinária. 3 ed. Santa Maria: 2007, p. 107.

MANUEL, C. S. Alterações clínicas, hematológicas e sorológicas de cães infectados por Ehrlichia canis. São Paulo, 2010. 67 f. Dissertação (Mestrado em Ciências). Departamento de Clínica Veterinária. Universidade de São Paulo. 
NELSON, R. W.; COUTO, C. G. Medicina interna de pequenos animais. 3. ed. Rio de Janeiro: Elsevier, 2006.

NELSON, R. W.; COUTO, C. G. Medicina interna de pequenos animais. 4. ed. Rio de Janeiro: Elsevier, 2010.

NOGUEIRA, F. S.; SILVA, C. L. S. P.; ARAUJO, S. A.; BORGES, J. H. R. Alterações no proteinograma de animais portadores de leishmaniose visceral canina. Ciên. Agr. Saúde. FEA, Andradina, v. 2, n. 2, jul-dez, 2002, p 25 - 27. 